\title{
Earnings and Linguistic Proficiency in a Bilingual Economy
}

\author{
Andrew Henley ${ }^{\dagger}$ \\ Rhian Eleri Jones ${ }^{\dagger}$
}

January 2003

\begin{abstract}
Bilingualism is a widespread phenomenon, yet its economic effects are under researched. Typically studies find that bilingual workers are disadvantaged. Governments often protect minority languages through official promotion of bilingualism, with potential economic consequences. This paper addresses the impact of bilingualism on earnings, using the example of Wales. Results show a positive raw differential of 8 to 10 per cent depending on definition of linguistic proficiency. The use of Welsh in the workplace is not directly productive. Nevertheless language choice and earnings appear to be endogenous. The differential can be entirely explained by a selection effect. This is consistent with the effectiveness of legislation to promote the minority language.
\end{abstract}

JEL Classification: J15, J24, J31

Keywords: Earnings, Language Choice, Human Capital

Word Count: 7631

${ }^{\dagger}$ School of Management and Business, University of Wales Aberystwyth.

Correspondence: Professor Andrew Henley, School of Management and Business, University of Wales Aberystwyth, Penglais, Aberystwyth, SY23 3DD, Wales. Tel +44 ( 0) 1970622504 , Email andrew.henley@aber.ac.uk

Acknowledgements: We would like to thank Reza Arabsheibani and Dennis Thomas for helpful advice at an early stage, and the University of Wales Economics Colloquium and Stephen Drinkwater for helpful comments. The data used in this paper were made available through the ESRC Data Archive. The British Household Panel Survey data were originally collected by the ESRC Institute for Social and Economic Research at the University of Essex. Neither the original collectors of the data nor the Archive bear any responsibility for the analyses or interpretations presented here. 


\section{Introduction}

It has been asserted that between one half and two-thirds of the world's population are bilingual (Crystal 1997) ${ }^{1}$. Many countries with substantial linguistic minorities protect the status of minority languages, and the cultural diversity associated with them, through the official adoption of bilingualism. Examples in the industrialised world include Canada, Belgium, Finland and Switzerland. These policies may have the effect of increasing the demand for bilingual employees.

Where pressure from a dominant majority language may mean that outflows from the stock of bilinguals exceeds inflows, a consequence is that there may be upward pressure on the earnings of bilinguals. This return may not necessarily reflect any increased productivity associated with language skill, but rather the cost of regulatory compliance. Indeed there is no particular reason why bilingualism should be directly associated with increased productivity - previous research has suggested that bilinguals suffer, other things equal, an earnings disadvantage because of the damage that learning a second language may do to proficiency in the dominant language (typically English). This paper seeks to identify whether there is a private return to having linguistic skills in more than one language in a bilingual economy, where bilingualism is subject to state protection. It also addresses the question of why any earnings differential between bilinguals and monolinguals arises. Our investigation is conducted using household survey data for Wales, a nation within the United Kingdom where policies aimed at arresting the decline in use of a minority language have been implemented over the last fifteen years. In Wales, subject to definition, approximately 20 per cent of the population are bilingual, speaking both English and Welsh (Cymraeg), a language belonging to the Western European Celtic languages group. 
The remainder of the paper is structured as follows. Section 2 reviews the very limited existing economic literature on bilingualism and provides some background to the Welsh language case, documenting the secular decline and current level of use of the language. Section 3 describes the data source used for the present work and sets out the methodology used to assess the scale of the economic return to bilingualism. Section 4 presents econometric results which support the conclusions outlined above. Section 5 provides a decomposition analysis of the raw earnings differential between bilinguals and Anglophones. Section 6 provides a concluding assessment of the findings.

\section{Background}

Multilingualism and bilingualism have been extensively researched in sociology and psychology, but attracted less attention in economics. For example Lazear (1999a, 1999b) explores the question of language dominance from an organisational perspective, discussing the pressures on global firms to avoid the transactions costs of hiring workers drawn from more than one language group. It is accepted as a starting premise that bilingual labour attracts a labour market premium. However there exists no empirical evidence to support this premise. Research in psychology and linguistics, although not conclusive, points to possible correlations between bilingualism and cognitive ability (Peal and Lambert 1962; Hakuta and Diaz 1985), and between bilingualism and verbal abilities (McLaughlin 1984). Some research, examining Swedish-Finnish bilinguals and bilingual children in Nigeria, points to improved cognition that leads on the higher levels of creativity and ability to organise information (Hamers and Blanc, 1989). Consequently there may exist unobservable qualitative differences in the human capital of bilinguals compared to monolinguals. 
However it cannot be ruled out that this association may also be interpreted as indicating that those with better cognition are more likely to become successful bilinguals.

A substantial body of research has established the empirical significance of linguistic skills in affecting labour market outcomes. Nearly all of this literature has been concerned with the important questions of the labour market assimilation of immigrants, the acquisition of (English) language skills and the value of immigrant human capital acquired through the medium of a foreign language (a far from exhaustive list of studies includes Dustmann, 1994; Chiswick and Miller, 1995; Friedberg, 2000; O’Leary et al., 2001; Shields and WheatleyPrice, 2002; Dustmann and Soest, 2002).

Previous research has been conduced on the economic impact of bilingualism, in particular though not exclusively, in Canada and in Israel (see, inter alia, Shapiro and Stelcner, 1981, 1997; Carliner, 1981; Robinson, 1988; Chiswick and Miller, 1994; Chiswick, 1998; Grin and Sfeddo, 1998; Grenier, 2000). Although bilingualism tends to be associated with higher levels of education, evidence suggests that bilingualism is associated, if anything, with an earnings disadvantage. Canadian research suggests a disadvantage for bilinguals (English and French) although this appears to diminish over time as government policy has supported the status of the French language (Shapiro and Stelchner 1997). Limited research has also been undertaken on indigenous language skills in Latin America, and finds that monolingual indigenous and bilingual workers are disadvantaged relative to monolingual Spanish speakers ((Patrinos et al., 1994; Chiswick et al., 2000). Research on bilingualism among native borne Americans (Chiswick and Miller, 1998) also finds that bilinguals suffer an earnings penalty. This is interpreted as indicating the level of English language proficiency of bilinguals suffers as a result of acquiring a second language, perhaps because of the effects 
of living in an ethnic enclave, or because bilinguals experience discrimination due to their difference accents or speech patterns.

Wales divides geographically into a bilingual area in the West and North and a largely (but not exclusively) monolingual Anglophone area in the South and East. There are now virtually no monolingual Welsh speakers in the population. The Welsh case typifies the case in which the use of a minority language is under severe pressure from the geographical proximity of a dominant language economy (in this case English). From an economic perspective the choice facing bilinguals is one of whether to abandon the minority language in favour of the dominant one. In effect this choice is the reverse of the language choice faced by immigrants. So bilingual societies, such as Wales, typify the converse of the immigrant enclave, where instead of the strength of the enclave serving to reduce the economic advantages of learning the dominant language (Chiswick and Miller, 1996, 2001), the state of the language in its "heartland" depends on the scale of the individual economic costs of abandoning bilingualism. The rate of spread of monolingualism will be inversely related to those costs.

At the time of writing the population of Wales comprises around a fifth bilingual Welsh/English speakers, although this proportion depends on definition. It has not always been so. Until well into the $19^{\text {th }}$ century much of Wales was monolingual Welsh-speaking, despite $16^{\text {th }}$ century legislation imposing English as the sole language of the law and public administration in Wales. The industrialisation of South and North East Wales from the mid $19^{\text {th }}$ century drew substantial immigration from English speaking Britain and Ireland. This, combined with a generally hostile attitude from government, resulted in the steady decline in the numbers of Welsh speakers. For example in 1847 a notorious government commission 
into the state of education in Wales concluded that "the Welsh language was ... a manifold barrier to the ... commercial progress of the people", and the subsequent Education Act of 1870 made the use of English compulsory in all schools in Wales. It was not until 1939 that the first Welsh-medium elementary school was re-established, but by this stage the damage had been done. The 1901 Census found that just under half of the population spoke Welsh and of these a third were monolingual. The proportion of Welsh speakers had fallen to around $25 \%$ by the time of the 1961 Census with only 26,000 monolingual Welsh-speakers remaining. This decline prompted political action resulting in the 1967 Welsh Language Act that established equal official and legal status for Welsh and English within Wales.

Despite this the decline continued until the 1980s (under 19\% bilingual, and $0.8 \%$ monolingual at the 1981 Census), prompting the establishment of Welsh-medium radio and television broadcasting. The 1988 Education Reform Act authorised some teaching of the language to all school students. Since the 1998 Education Act the teaching of Welsh has become a core subject as either first or second language to the age of 16 within Wales. The explicit intention of this legislation was to arrest the decline in the use of the minority language and to preserve and improve awareness of the diverse Welsh-medium cultural heritage. As a consequence recent census data suggests that the decline in the proportion of Welsh speakers among younger age groups has now been arrested. ${ }^{2}$ Welsh-medium education is achieving growing popularity, even from monolingual Anglophone parents. However important unresolved questions remain about the effectiveness of the teaching of Welsh in Anglophone areas, and whether for less able pupils the teaching of Welsh detracts from the acquisition of basic English language skills. 
The 1993 Welsh Language Act established the Welsh Language Board with a statutory responsibility to promote the use of the language, to require all public bodies in Wales to provide an equal service in English and Welsh, and to monitor the implementation of bilingual policies in all public bodies. This legislation in effect enshrines "official" bilingualism. The 1993 legislation has also allowed employers to adopt employment policies that explicitly state that bilingualism is either a "desirable" or "essential" skill. All counties in the Welsh-language "heartland" in the north and west (defined as the counties of Gwynedd, Ynys Môn (Anglesey), Ceredigion, Sir Caerfyrddin (Carmarthenshire) and Sir Ddinbych (Denbighshire)) have now adopted this principle for many local government positions, and it is gaining ground amongst voluntary sector employers and some private sector employers. One consequence of this legislation is that a bilingual candidate may have a recruitment advantage over a monolingual Anglophone with otherwise identical skills, regardless of any earnings premium for bilingualism as a skill. The creation of a regional parliament (the National Assembly for Wales) in 1998 has further supported the position of the language by restoring Welsh to its pre- $16^{\text {th }}$ century status, as a language of government. So in Wales, as in other bilingual states or regions policies aimed at maintaining and improving proficiency in the endangered language are a matter of major concern and public debate.

The present study uses data from the last few months of the $20^{\text {th }}$ century. This is an interesting point at which to examine the impact of bilingualism on earnings because by 1999 the first cohorts of children educated from the age of five (wholly or partly) through the medium of Welsh under the provisions of the 1988 legislation will be approaching the age of 16, at which they may first enter the labour force. The date also follows closely the establishment of the National Assembly, and the impact that this body has had on the public presence of bilingualism within Wales. Bilingual skills are in growing demand from public 
sector organisations and companies who are required to have a bilingual "front-of-house" capability and official translation facilities, and from Welsh language broadcasting and media, as well as within the teaching profession.

\section{Data and Methodology}

Although data on language use is collected in the UK through the decennial Census, it includes little detail on individual labour market characteristics and no information on earnings. Consequently previous research has focused exclusively on economic activity and on the distribution of bilinguals across the industrial and occupational structure. One of the main conclusions, consistent with a greater demand for bilingual skills in the labour market, is that the bilingual Welsh are, controlling for educational and demographic characteristics, less likely to be unemployed (Blackaby and Drinkwater, 1996).

The only current data source that allows the matching of language use to earnings, along with a rich set of information on individual characteristics is the 1999 wave of the British Household Panel Survey. The 1999 wave included the recruitment of an additional sample of 1357 households in Wales (in addition to the existing 317 households in Wales up to that point) in order to better inform policy-making for the newly-establishment regional government. These provide a sample of 1283 paid employees between the ages of 16 and 65 . Of these 1070 provide earnings data. 54 observations were omitted with reported hourly earnings below $£ 1$ or above $£ 40$, leaving a sample for analysis of 1016 .

Respondents were each asked about the following Welsh language skills: ability to understand spoken Welsh, ability to speak Welsh, ability to read Welsh and ability to write 
Welsh. These were coded into hierarchical order to eliminate inconsistent responses. ${ }^{3}$ So ability to speak Welsh is defined as conditional on ability to understand spoken Welsh, and ability to read Welsh is defined as conditional on ability to speak it, etc. In addition respondents were asked about their use of Welsh in the workplace. Table 1 provides sample information on the use of Welsh from these data. $24 \%$ of the sample report that they can understand spoken Welsh. However this proportion falls as language skill increases, such that only $15 \%$ report that they can write Welsh, as well as understand, speak and read it. Almost $15 \%$ of the sample report that they use Welsh for some proportion of their time at work. In the sample bilinguals and Anglophones have very similar demographic characteristics. There is no significant difference in the average age of the two groups. The only differences of note are that women are slightly more likely to be bilingual (in the sample $57 \%$ of those who report they can speak as well as understand Welsh are female, whereas $51 \%$ of those who cannot are female), and that bilinguals are more likely to have been educated to university or college degree level (15\% of those who report they can speak as well as understand Welsh have a degree, $10 \%$ of those who cannot have a degree).

Earnings are defined as usual monthly gross pay divided by $4.33 *$ (normal plus overtime weekly hours). The mean differential defined on the basis of ability to understand Welsh is 60 pence per hour or nearly 9 per cent. The differential widens for employees who can speak, read and write Welsh. For those who can write (as well as understand, speak, and read) Welsh, the raw differential rises to 75 pence an hour or nearly 11 per cent. There is, in the sample, a greater dispersion of earnings amongst bilingual employees compared to Anglophone ones. ${ }^{-1}$ However, for those who report Welsh use at work the differential over Anglophone workers is much lower at only 36 pence an hour. So are bilingual workers in Wales more productive? This latter statistic would suggest that bilingualism is not associated 
with greater productivity within the workplace, and that we must look for other channels through which bilingualism in Wales affects earnings.

The raw earnings differential observed between monolinguals and those with Welsh language skills may arise simply because bilingual employees have, on average, higher levels of those characteristics that are rewarded in the labour market, including education and experience. In order to assess whether there is a genuine premium to bilingual skills, it is necessary to control for these human capital and other characteristics. To do this standard earnings functions of the following form are estimated:

$$
\ln W_{i j}=X_{i j} \beta_{j}+\varepsilon_{i j} \quad i=1 \ldots n ; \quad j=w, e
$$

where $W$ is hourly earnings, $X$ contains human capital and other controls, $\beta$ is a vector of coefficients and $\varepsilon$ is an error term assumed independent of $X$. $i$ subscripts individuals in the sample, $j$ denotes membership of the bilingual sub-group (w) or the monolingual Anglophone sub-group (e).

Early studies of the effect of linguistic proficiency on earnings pool observations for both sub-groups and allow bilingual skills to take the form of an intercept-shift effect. This measures the value of the difference between the wage opportunities open to a bilingual and an Anglophone employee with the same measured human capital characteristics. So the earnings function can be represented as:

$$
\ln W_{i}=X_{i} \beta+\partial L_{i}+\varepsilon_{i}^{\prime}
$$


where $L_{i}=1$ if individual $i$ is bilingual and 0 otherwise and $\varepsilon_{i}^{\prime}=L_{i} \varepsilon_{i w}+\left(1-L_{i}\right) \varepsilon_{i e}$. OLS estimation of (2) will only provide unbiased estimates of the bilingual wage premium, $\delta$, if there is no correlation between unmeasured human capital characteristics in the error term and language skill. However this assumption is a major difficulty since language choice and earnings are likely to be endogeneous (see Chiswick and Miller (1995) for a more detailed, formal discussion of language choice). One solution is to find appropriate instrumental variables for the language dummy variable and use an IV estimator. However such an approach assumes that any returns to a language skill are not individual-specific, and that the impact of linguistic proficiency on earnings is assumed to be quite independent of any other skills or abilities. If returns to bilingualism are individual-specific then an IV estimator will not identify the average return to language skill.

In order to relax this potentially restrictive assumption equation (1) can be estimated for each group in conjunction with a switching mechanism to model individual choice of language proficiency. The individual worker conditions the choice of language skill on the perceived returns to being monolingual or bilingual. The processes determining earnings in each linguistic group can be distinct. Let $I_{i}^{*}$ denote a latent variable capturing the net advantage after any costs of retaining/learning the minority language. State intervention will impact on $I_{i}^{*}$ to the extent that it influences the actual and psychic costs of language acquisition or retention. In the case of Wales, government policy allows for some subsidy for individuals to acquire and/or maintain linguistic skill in Welsh. Policy may also shift individual perceptions about the value of the language and the degree of social approval or stigma associated with speaking it. Define an indicator variable $I$ capturing whether an individual is bilingual as follows: $I_{i}=1$ if $I_{i}^{*} \geq 0$ and 0 otherwise. Thus 
$\ln W_{i}=\ln W_{i w}$ when $I_{i}=1$ and $\ln W_{i}=\ln W_{i e}$ when $I_{i}=0$. Assume that $I_{i}$ can be modelled by the following reduced form relationship:

$$
\operatorname{Pr}\left(I_{i}=1\right)=\operatorname{Pr}\left(X_{i} \gamma_{1}+Z_{i} \gamma_{2}+v_{i} \geq 0\right)=\operatorname{Pr}\left(\psi_{i}+v_{i} \geq 0\right)
$$

$Z$ are additional identifying instruments and $\gamma_{1}$ and $\gamma_{2}$ are coefficient vectors. Under the assumption that $v_{i}$ is an error term distributed $N\left(0, \sigma^{2}\right)$, then (3) can be estimated as a probit model. As earnings are only observed in one of the two states, a Heckman (1979) two-stage procedure can be used, assuming $v_{i}$ and $\varepsilon_{i}$ are jointly normally distributed, to estimate selectivity-corrected earnings functions for each linguistic group:

$$
\ln W_{i w}=X_{i w} \beta_{w}^{\prime}+\delta_{w} \lambda_{w}+\varepsilon_{i w}
$$

and

$$
\ln W_{i e}=X_{i e} \beta_{e}^{\prime}+\delta_{e} \lambda_{e}+\varepsilon_{i e}
$$

where $\lambda_{w}=\frac{\phi\left(\psi_{i}\right)}{\Phi\left(\psi_{i}\right)}$ and $\lambda_{e}=\frac{-\phi\left(\psi_{i}\right)}{1-\Phi\left(\psi_{i}\right)}$ with $\phi$ and $\Phi$ the density and cumulative distribution functions of a standard normal variable respectively. The terms $\delta_{w} \lambda_{w}$ and $\delta_{e} \lambda_{e}$ capture the relative earnings (dis)advantage enjoyed by bilingual and Anglophone speakers from their language skill-specific human capital. Human capital may be language skill-specific and the choice to learn or retain the minority language may be endogenously determined with earnings. Under these assumptions and appropriate selection of identifying instruments, the model described in equations (4) to (6) will provide unbiased estimates of the effect of bilingualism on earnings. 


\section{Econometric Results}

The earnings model is estimated with the inclusion of the various control variables for human capital and other characteristics. Human capital variables include binary variables for education to university level ("Degree"), sub-degree vocational "higher national diploma" qualifications ("HND”), and examination passes at age 18 ("A-levels”) and at age 16 ("O-

levels/GCSE's")! . The omitted educational category is no educational qualifications at age 16 or above. Years of experience, defined as age at interview minus the age at which the individual left full-time education, is included as a level and a square. Occupational influences are captured though binary variables for professional or managerial employment, skilled employment and semi-skilled employment, as well as employment in the public sector. The omitted category here is therefore private sector unskilled workers. Preliminary investigation of the possible effects of industrial affiliation found that the only significant (negative) influence on earnings arose in the transport and communications sector, and so this binary category is included. The earnings literature typically finds that large employers pay more. So binary variables for two workplace size categories (100-999 and 1000 and above) are included. A self-reported indication of trade union membership captures the effect on earnings of any union bargaining power. Demographic variables for gender, membership of a non-white ethnic minority and marital/cohabitation status are also included to capture possible discrimination effects on earnings.

Table 2 reports key results from OLS estimation of equation (2). After discarding two individuals with missing characteristics information, a sample of 1014 is available for estimation purposes. In all cases all the various characteristics attract statistically well determined, plausibly signed and sized coefficients. Full results are available on request. 
Columns (1) to (4) report results exploring the effects of the different definitions of linguistic proficiency. The effect on earnings of the ability to understand spoken Welsh is positive but it is not statistically significant. However the coefficients are larger and statistically significant for higher-level language proficiency, particularly for the ability to read and write Welsh. The earnings advantage for being able to read or write Welsh is estimated as 6 to 7 percent, and is therefore over two-thirds of the unadjusted mean log earnings differential. The regression in column (5) includes all four definitions of language proficiency in order to assess the marginal impact on earnings of the different proficiencies. Because of the hierarchical construction of the linguistic proficiency variables the reported individual coefficient estimates in column (5) sum to the reported coefficient in column (4). However, due to multicollinearity, none of these separate effects is statistically significant. The ability to speak but not to read or write Welsh may slightly reduce earnings relative to Anglophones (coefficient: -0.04). A positive advantage to bilingualism appear in particular to arise from the possession of written language skills (coefficient: +0.075 ).

Finally column (6) investigates whether there is an earnings advantage associated with the use of Welsh in the workplace. The coefficient estimate is negative but not statistically significant. So bilingualism does not appear directly to enhance productivity in the workplace. ${ }^{6}$ This suggests that the earnings advantage obtained by bilinguals reflects other unobserved human capital characteristics associated with bilingualism or the effects of selectivity bias. In fact this conclusion is confirmed by instrumental variable estimates using an instrument set discussed below (not reported but available in Henley and Jones, 2001). These show that any estimated bilingual earnings premium obtained using OLS disappears once choice of language skill is assumed endogenous. The puzzle therefore is why 
bilingualism appears to be associated with an earnings premium, even though bilingual language skills in the workplace are not.

So bilingualism may impart some earnings advantage that cannot be captured by differences in returns to measurable characteristics, but which appears in equations (5) and (6) as a selection effect. In other words those who choose to adopt/retain bilingual skills are able to obtain higher earnings than the average worker, other things equal. To investigate this possibility, the choice of language proficiency is identified by various background characteristics. Parental background may display a strong association with the ability to speak Welsh. In particular whether an individual's parents where born in Wales may be important. The list of identifying instruments includes dummy variables for whether father and mother were born in Wales. In addition, and given our conclusions so far, parents may have been more likely to have placed greater overall emphasis on the use of the Welsh language if they worked on their own rather than in a Anglophone workplace. So the instrument list also include binary variables for whether father and mother were self-employed when the individual was 14 years of age.

Chiswick and Miller (2001) identify the importance of linguistic concentration on the language adjustment of immigrants in the United States labour market. Applying the equivalent "enclave" argument in the present case motivates the choice of two further instruments. Decisions in the past concerning choice of spouse are likely to be motivated by linguistic concerns, and the presence of a bilingual spouse may affect the current decision to acquire or retain the second language. So a dummy variable for whether the spouse is bilingual (conditional on married or cohabiting status) is included in the instrument list. 
Finally a measure of the proportion of Welsh-speakers by relevant age group in the county of residence, obtained from UK population survey estimates for 1997, is included.

Table 3 presents key results from probit estimates of equation (4) for each definition of linguistic proficiency. These capture in reduced form a model of choice of linguistic proficiency. The estimating equation includes all the earnings function regressors as covariates as well as the additional identifying variables described above. Only the coefficients for the additional identifying variables are reported in the Table. Full results are available on request. Although these equations are reduced form, they reveal that a number of characteristics are associated with bilingualism. These include the possession of a university degree (marginal effect +0.09 to $+0.13^{\text {孟 }}$ ) or HND qualification $(+0.14$ to +0.25$)$, employment in the public sector $(0.0$ to +0.05$)$, being married or cohabiting $(0.0$ to -0.06$)$, having a father born in Wales $(0.0$ to +0.06$)$, having a mother born in Wales $(0.0$ to +0.08$)$, and having a bilingual spouse $(+0.06$ to +0.18$)$. A ten-percentage point increase in the proportion of Welsh speakers in the same age group and county is associated with an increase in the probability of being bilingual of between 0.04 and 0.08 . In all cases reported likelihood ratio statistics show that the additional identifying instruments are highly jointly statistically significant.

Table 4 reports selectivity-corrected earnings function estimates again for each definition of linguistic proficiency and in each case for bilinguals and Anglophones. The selectivity correction coefficient is statistically significant for the bilingual sample, except in the case with bilingualism is defined as use of Welsh at work. This result accords with the pattern of significance of the bilingualism controls in the OLS results. It indicates that there is positive selection for bilingual workers, even though bilingual skills are not directly productive in the workplace. For the Anglophone sample the selectivity correction coefficient 
is never significant. There are some differences in the rates of return to particular characteristics in the two markets, but these differences are not particularly robust to the definition of linguistic proficiency. For example those who can understand spoken Welsh enjoy a $52 \%$ return to having a university or college degree, whereas the return is only $37 \%$ for those who cannot. However, as the definition of linguistic proficiency is widened to include the possession of reading and writing skills in Welsh, this difference disappears. Of particular note is that any disadvantage to being female diminishes as linguistic proficiency moves from the lower to the higher definitions. Also it is notable that there is no significant earnings advantage to being employed by a large employer for bilingual employees.

\section{Decomposition of the Earnings Differential}

So the difference in earnings between bilinguals and monolinguals in Wales appears to arise principally because of selection. Bilinguals have an earnings advantage even though bilingual skills are not directly productive. This conclusion stands in contrast to previous research. In order to place this into context an earnings decomposition analysis is performed on the estimates reported in Table 4. This method is as described in Oaxaca and Ransom (1994). The difference in mean log earnings between bilingual and Anglophone employees can be decomposed as:

$$
\ln \bar{W}_{w}-\ln \bar{W}_{e}=\left[\delta_{w} \bar{\lambda}_{w}-\delta_{e} \bar{\lambda}_{e}\right]+\left[\hat{\beta}^{*}\left(\bar{X}_{w}-\bar{X}_{e}\right)\right]+\left[\bar{X}_{w}\left(\hat{\beta}_{w}-\hat{\beta}^{*}\right)+\bar{X}_{e}\left(\hat{\beta}^{*}-\hat{\beta}_{e}\right)\right]
$$

where $\hat{\beta}^{*}=\Omega \hat{\beta}_{w}+(1-\Omega) \hat{\beta}_{e}$ and $\Omega=\left(X_{w}^{\prime} X_{w}+X_{e}^{\prime} X_{e}\right)^{-1} X_{w}^{\prime} X_{w} . \hat{\beta}^{*}$ is an estimate of the earnings returns to particular characteristics that might apply under a single hypothetically competitive labour market. It is constructed as a weighted average of the two estimated 
coefficient vectors using $\Omega$ as weights. The first term on the right-hand side represents the difference in earnings due to self-selection of individuals into either of the two linguistic groups. The second term represents that part of the differential due to the two groups having different average endowments of measured human capital and other characteristics. It may be further decomposed to establish the contributions of particular characteristics such as education and experience. The third term represents the earnings advantage or disadvantage of bilingual employees over Anglophone employees not due to differences in endowments of characteristics. It divides into two components. The first is the estimated (dis)advantage of being bilingual relative to what could be earned in a single hypothetical labour market in which all employees retain their given characteristics apart from difference in language proficiency. The second is the estimated (dis)advantage of being Anglophone relative to what could be earned in that hypothetical single labour market.

Table 5 reports the results of this decomposition analysis for each definition of language proficiency. The results are quite striking. The geometric mean wage differential to be explained is of the order of 8 to 10 per cent for the different language skills, although only 3 per cent for the use of Welsh in the workplace. The selection effect is so strong that it explains well over 100 per cent of the differential in each case. Consequently if each of these two groups of employees had been drawn randomly from the population in the absence of any effects of linguistic proficiency, bilinguals would be paid a little less. This is consistent with previous research that suggests that bilinguals may suffer a productivity disadvantage. However reinforcing the selection effect is the fact that bilingual employees have on average higher endowments of remunerated characteristics. This contributes a further 27 to 45 per cent of the differential depending on definition of language proficiency and a further 114 per cent of the differential for those who use Welsh at work. The principal contributory factors 
here are higher levels of average education, higher occupational characteristics and the fact that there are a lower proportion of ethnic minority individuals among the bilingual group.

Bilinguals are disadvantaged because they are paid lower levels of remuneration for given characteristics. The bulk of this effect arises from a relative disadvantage compared to that which might occur a hypothetical unified labour market, rather than from the relative earnings advantage of Anglophones. The disadvantage is of the order of 55 to 65 per cent of the differential depending on the definition of language proficiency skill. It rises to 167 per cent of the smaller differential enjoyed by those who use Welsh at work. So although bilingual employees have higher levels of educational attainment and are more likely to be in higher paid occupations, they receive less pay, ceteris paribus, for a given characteristic than those in the Anglophone labour market. This could be intrepreted as discrimination; it might also be interpreted meaning that bilinguals are less able to convert given characteristics into productive skills.

\section{Conclusions}

Limited previous research on the economic impact of bilingualism suggests that it disadvantages workers. However such adverse productivity effects may be offset if government intervention seeks to protect a minority language through regulation. Previous research has not investigated this possibility. This paper has sought to redress this using Wales as a case study. Our data point to a raw earnings differential of 60 to 75 pence per hour, or 8 to $10 \%$, in favour of bilinguals. However this differential is substantially smaller for those who report the use of Welsh in the workplace compared to those whose workplace is monolingual. This latter conclusion suggests strongly that bilingual workers are not 
necessarily more productive, but that employers have a preference for bilingual workers for other reasons, perhaps in order to conform to government regulation.

Simultaneous estimation of earnings functions with a language choice equation finds significant evidence for the influence of individual self-selection into linguistic group on earnings. A Oaxaca-Ransom earnings decomposition was used to quantify the components of the earnings differential. The results show over 100 per cent of the differential can be explained by this sample selection effect, i.e. a comparative earnings advantage enjoyed by bilinguals resulting from their inheritance of or choice of linguistic skill. This implies that bilinguals and monolinguals cannot be considered randomly allocated between the two labour markets.

In addition to the sample selection effect, the possession on average of higher levels of remunerated characteristics advantages bilinguals over Anglophones. In particular they have higher average levels of educational and occupational attainment. The scale of this "endowment" effect is of the order of 3 to $4 \%$ of earnings, or a third to a half of the raw differential. However bilinguals are underpaid compared to Anglophones, for given characteristics. This conclusion is consistent with earlier research on the damaging effect of bilingualism on productivity in North America. The scale of the effect in Wales is around a third to a half of the raw differential. It may capture an earnings discrimination effect arising from employers taking advantage of the relative immobility of bilingual workers, due to the value of living where the minority language can be spoken. Alternatively it may suggest that bilinguals are less productive given particular characteristics. Our conclusions here point to the need for further research on this question. 
Given the importance of the selection effect in the decomposition of the raw positive bilingual earnings differential, how might we explain its existence? The selection effect is consistent with the effect of state intervention to promote bilingualism. If a minority language is deemed to be worth preserving, then these results suggest that protective legislation can create an effective economic incentive and overcome any bilingual productivity disadvantage. Consequently, because language choice and earnings are endogenous, government intervention appears to offer an effective method for protecting minority linguistic skills.

However other explanations are possible. There may be a substantial bilingual "insider" effect in the labour market. Bilinguals may be both better informed about labour market opportunities as they arise, and also enjoy a selection effect operating in their favour by being better known to potential employers. There are qualitative differences in the human capital of bilinguals compared to Anglophones. This is consistent with findings from psychological and socio-linguistic research that in childhood bilinguals acquire improved cognitive ability. This possibility, however, must be set against the absence of a differential for bilingualism in the workplace. The ability to use both languages in employment is not in itself as highly rewarded. Rather bilingual workers are rewarded for the possession of unobservable human capital that correlates with, but is different from, the possession of bilingual skills. 


\section{Footnotes}

${ }^{1}$ It should be noted that Crystal does not provide detailed evidence to support this statement.
${ }^{2}$ The 1981 Census reports that $15.0 \%$ of those aged 16 to 24 were able to speak Welsh. By 1991 this had risen to $17.1 \%$ (UK Office for National Statistics, as reported in the Digest of Welsh Statistics, 2002 Edition). Larger increases were recorded for school aged children. A slight overall decline in the proportion of the whole population able to speak Welsh arises from the decline in Welsh language use amongst older age groups, particularly those over 45 years of age.

${ }^{3}$ Misreporting of language skill is recognised as a problem in all surveys of this nature, including Census data. Dustmann and van Soest (2001) discuss in detail the problems caused by misclassification

${ }^{4}$ The standard deviations of log hourly earnings for those who can speak, read and write Welsh and for Anglophones are 0.498 and 0.473 respectively.

5 Until the late 1980s British school pupils sat either O-level examinations or CSE examinations depending on ability at age 16. Subsequently these two qualifications were combined into the GCSE qualification. The variable measures the attainment of any of these.

${ }^{6}$ It is possible that education and earnings levels are endogenously determined, since individuals make educational choices once they become aware of their different earnings opportunities. This was investigated by substituting the educational controls with educational background variables (parental occupational status and type of school attended). These alternative OLS estimates are reported in Henley and Jones (2001). Under this approach the earnings advantage associated with bilingualism is found to be of a comparable magnitude to that reported in Table 2.

7 This is the closest definition available to working as a "sole-trader". In our data source nearly $70 \%$ of those currently self-employed work as sole traders.

${ }^{8}$ Calculated as the impact on the probability of having Welsh language skills (as defined by the relevant dependent variable) of a discrete change. Where the coefficient is insignificant in one of more regressions the range given includes zero.

${ }^{9}$ Our results are therefore consistent with Drinkwater and O'Leary (1997), who find, using 1991 Census data, that Welsh speakers are less likely to be unemployed. 


\section{Bibliography}

D.H. Blackaby and S. Drinkwater (1996), "Welsh-speakers and the labour market", Contemporary Wales, 9:158-170.

D. Crystal (1997), English as a Global Language, Cambridge: Cambridge University Press.

G. Carliner (1981), "Wage difference by language group and the market for language skills in Canada", Journal of Human Resources, 16(3): 384-399.

B.R. Chiswick (1998), "Hebrew language usage: determinants and effects on earnings among immigrants in Israel", Journal of Population Economics, 11: 253-271.

B.R. Chiswick and P.W. Miller (1994), "Language choice among immigrants in a multilingual destination", Journal of Population Economics, 7: 119-131.

B.R. Chiswick and P.W. Miller (1995), "The endogeneity between language and earnings: international analyses", Journal of Labor Economics, 13(2): 246-288.

B.R. Chiswick and P.W. Miller (1996), "Ethnic networks and language proficiency among immigrants", Journal of Population Economics, 9:19-35.

B.R. Chiswick and P.W. Miller (1998), "The economic cost to native-born Americans of limited English language proficiency", report to the Center for Equal Opportunity.

B.R. Chiswick and P.W. Miller (2001), "Do enclaves matter in immigrant adjustment?", mimeo, Department of Economics, University of Illinois at Chicago (February).

B.R. Chiswick, H.A. Patrinos and M.E. Hurst (2000), "Indigenous language skills and the labor market in a developing country: Bolivia", Economic Development and Cultural Change, 48: 349-367.

S. Drinkwater and N. O'Leary (1997), "Unemployment in Wales: does language matter?", Regional Studies, 31(6): 583-591.

C. Dustmann (1994), "Speaking fluency, writing fluency and earnings of migrants", Journal of Population Economics, 7:133-156.

C. Dustmann and A. van Soest (2001), "Language fluency and earnings: estimation with misclassified language indicators", Review of Economics and Statistics, 83(4): 66374.

C. Dustmann and A. van Soest (2002), "Language and the earnings of immigrants", Industrial and Labor Relations Review, 55(3): 473-92.

R.M. Friedberg (2000), "You can't take it with you? Immigrant assimilation and the portability of human capital", Journal of Labor Economics, 18: 221-251. 
G. Gernier (2000), "Linguistic and economic characteristics of Francophone minorities in Canada: a comparison of Ontario and New Brunswick", Journal of Multilingual and Multicultural Development 18: 285-301

F. Grin and C. Sfreddo (1998), "Language-based earnings differentials on the Swiss labour market: is Italian a liability?", International Journal of Manpower, 19(7): 520-532.

K. Hakuta and R.M. Diaz (1985), "The relationship between the degree of bilingualism and cognitive ability: a critical discussion and some new longitudinal data", in (ed.) Nelson, K.E., Children's Language, Erlbaum, Hillsdale NJ.

J.F. Hamers and M.H.A. Blanc (1989), Bilinguality and Bilingualism, Cambridge University Press, Cambridge.

A. Henley and R.E. Jones (2001), "Gyflog a gallu ieithyddol mewn economi ddwyieithog/Earnings and linguistic ability in a bilingual economy", Research Paper No. 2001-18, University of Wales Aberystwyth, School of Management and Business.

E. Lazear (1999a), “Culture and language”, Journal of Political Economy, 107: S95-S126.

E. Lazear (1999b), "Globalisation and the market for team-mates", Economic Journal, 109:C15-C40.

B. McLaughlin (1984), Second-language acquisition in childhood, $2^{\text {nd }}$ Ed. Erlbaum, Hillsdale NJ.

R.L. Oaxaca and M.R. Ransom (1994), "On discrimination and the decomposition of wage differentials", Journal of Econometrics, 61:5-21.

N.C. O'Leary, P.D. Murphy, S.J. Drinkwater and D.H. Blackaby (2001), "English Language Fluency and the Ethnic Wage Gap for Men in England and Wales", Economic Issues, 6: 21-32.

H.A. Patrinos, E. Velez and G. Psacharopoulos (1994), "Language, education and earnings in Asunción, Paraguay", Journal of Developing Areas 29: 57-68.

E. Peal and W.E. Lambert (1962), "The relation of bilingualism to intelligence", Psychological Monographs, 76:1-23.

C. Robinson (1988), "Language choice: the distribution of language skills and earnings in a dual-language economy", Research in Labor Economics 9:53-90.

M. Shields and S. Wheatley-Price (2002), "The English language fluency and occupational success of ethnic minority immigrant men living in English metropolitan areas", Journal of Population Economics, 15:137-160.

D. M. Shapiro and M. Stelcner (1981), "Male-female earnings differentials and the role of language in Canada, Ontario, and Quebec, 1970", Canadian Journal of Economics/Révue canadienne d'Economique 14(2): 341-348. 
D.M. Shapiro and M. Stelcner (1997), "Language and earnings in Quebec: trends over twenty years, 1970-1990”, Canadian Public Policy - Analyse de Politiques, 23(2): 115-140. 
Table 1: Employees with Bilingual Skills

\begin{tabular}{lcccccc}
\hline & \multicolumn{2}{c}{ Male } & \multicolumn{2}{c}{ Female } & \multicolumn{2}{c}{ Total } \\
& $\mathrm{N}$ & $\%$ & $\mathrm{~N}$ & $\%$ & $\mathrm{~N}$ & $\%$ \\
\hline Understands spoken Welsh & 109 & 22.2 & 134 & 25.5 & 243 & 23.9 \\
$\ldots$.. and speaks Welsh & 79 & 16.1 & 104 & 19.8 & 183 & 18.0 \\
$\ldots$... and reads Welsh & 71 & 14.5 & 96 & 18.3 & 167 & 16.4 \\
$\ldots$... and writes Welsh & 65 & 13.2 & 86 & 16.4 & 151 & 14.9 \\
Uses Welsh at work & 65 & 13.2 & 85 & 16.2 & 150 & 14.8 \\
\hline
\end{tabular}

Source: Computed from British Household Panel Survey 1999

Sample size: 1016 
Table 2: OLS estimates: Dependent variable In(hourly earnings)

\begin{tabular}{|c|c|c|c|c|c|c|}
\hline & (1) & (2) & (3) & (4) & (5) & (6) \\
\hline Understands spoken & 0.0425 & & & & 0.0183 & \\
\hline Welsh & $(0.0266)$ & & & & $(0.0477)$ & \\
\hline ....and speaks Welsh & & 0.0490 & & & -0.0395 & \\
\hline ....and reads Welsh & & $(0.0296)^{+}$ & $\begin{array}{c}0.0607 \\
(0.0307)^{*}\end{array}$ & & $\begin{array}{c}(0.0812) \\
0.0155 \\
(0.0998)\end{array}$ & \\
\hline .... and writes Welsh & & & & $\begin{array}{c}0.0692 \\
(0.0319) *\end{array}$ & $\begin{array}{c}0.0749 \\
(0.0837)\end{array}$ & \\
\hline Uses Welsh at work & & & & & & $\begin{array}{c}-0.0088 \\
(0.0322)\end{array}$ \\
\hline Intercept & $\begin{array}{c}1.2656 \\
(0.0498)^{*}\end{array}$ & $\begin{array}{c}1.2657 \\
(0.0500)^{*}\end{array}$ & $\begin{array}{c}1.2636 \\
(0.0497)^{*}\end{array}$ & $\begin{array}{c}1.2624 \\
(0.0497)^{*}\end{array}$ & $\begin{array}{c}1.2621 \\
(0.0499)^{*}\end{array}$ & $\begin{array}{c}1.2791 \\
(0.0498)^{*}\end{array}$ \\
\hline R-squared & 0.4621 & 0.4622 & 0.4629 & 0.4633 & 0.4634 & 0.4608 \\
\hline $\mathrm{F}$ & $44.95 *$ & $44.97 *$ & $45.08^{*}$ & $45.16^{*}$ & $38.91 *$ & $44.71 *$ \\
\hline
\end{tabular}

Source: Computed from British Household Panel Survey,

+ denotes significant at $10 \%$; * at $5 \% . \mathrm{N}=1014$.

Note: omitted coefficients available on request 
Table 3: Reduced Form Selection Probit Equations

\begin{tabular}{lccccc}
\hline Dependent Variable: & $\begin{array}{c}\text { Understands } \\
\text { spoken } \\
\text { Welsh }\end{array}$ & $\begin{array}{c}\text {...and } \\
\text { speaks } \\
\text { Welsh }\end{array}$ & $\begin{array}{c}\ldots \text { and reads } \\
\text { Welsh }\end{array}$ & $\begin{array}{c}\ldots \text { and } \\
\text { writes } \\
\text { Welsh }\end{array}$ & $\begin{array}{c}\text { Uses Welsh } \\
\text { at work }\end{array}$ \\
& 0.1661 & 0.2488 & 0.3042 & 0.3063 & 0.3300 \\
Father self-employed & $(0.1652)$ & $(0.1700)$ & $(0.1698)^{+}$ & $(0.1754)^{+}$ & $(0.1840)^{+}$ \\
& 0.2461 & 0.2633 & 0.3234 & 0.1954 & 0.4129 \\
Mother self-employed & $(0.2401)$ & $(0.2516)$ & $(0.2507)$ & $(0.2614)$ & $(0.2601)$ \\
Father born in Wales & 0.4201 & 0.3642 & 0.3258 & 0.3078 & 0.4057 \\
& $(0.1299)^{*}$ & $(0.1435)^{*}$ & $(0.1488)^{*}$ & $(0.1544)^{*}$ & $(0.1608)^{*}$ \\
Mother born in Wales & 0.1806 & 0.3400 & 0.5001 & 0.5122 & 0.3794 \\
& $(0.1322)$ & $(0.1473)^{*}$ & $(0.1547)^{*}$ & $(0.1617)^{*}$ & $(0.1656)^{*}$ \\
\% Welsh speakers in & 0.0277 & 0.0272 & 0.0268 & 0.0286 & 0.0308 \\
age group and county & $(0.0026)^{*}$ & $(0.0026)^{*}$ & $(0.0026)^{*}$ & $(0.0027)^{*}$ & $(0.0028)^{*}$ \\
Spouse bilingual & 0.5691 & 0.6323 & 0.4632 & 0.3191 & 0.7476 \\
& $(0.1449)^{*}$ & $(0.1613)^{*}$ & $(0.1624)^{*}$ & $(0.1785)+$ & $(0.1940)^{*}$ \\
& & & & & \\
Log likelihood & -424.10 & -348.12 & -331.00 & -306.51 & -278.36 \\
Chi ${ }^{2}(6)$ & $188.33^{*}$ & $175.52^{*}$ & $158.45^{*}$ & $156.54^{*}$ & $184.85^{*}$ \\
\hline
\end{tabular}

Source: Computed from British Household Panel Survey, 1999.

Notes: + denotes significant at $10 \%$; $*$ at $5 \% . \mathrm{N}=1014 . \mathrm{Chi}^{2}(6)$ is a $\mathrm{LR}$ test of joint significance of these identifying instruments excluded from the earnings equations. Other omitted coefficients available on request. 
Table 4: Heckman estimates: Dependent variable $\log ($ hourly earnings)

\begin{tabular}{|c|c|c|c|c|c|c|}
\hline \multirow{3}{*}{ Sample: } & (1) & (2) & (3) & (4) & (5) & (6) \\
\hline & \multicolumn{2}{|c|}{$\begin{array}{l}\text { Understands spoken } \\
\text { Welsh }\end{array}$} & \multicolumn{2}{|c|}{... and speaks Welsh } & \multicolumn{2}{|c|}{... and reads Welsh } \\
\hline & Yes & No & Yes & No & Yes & No \\
\hline $\mathrm{N}$ & 242 & 772 & 182 & 832 & 166 & 848 \\
\hline \multirow[t]{2}{*}{ Degree } & 0.5176 & 0.3720 & 0.4747 & 0.3981 & 0.4193 & 0.4103 \\
\hline & $(0.0715)^{*}$ & $(0.0501)^{*}$ & $(0.0834) *$ & $(0.0474)^{*}$ & $(0.0853) *$ & $(0.0473)^{*}$ \\
\hline \multirow[t]{2}{*}{ HND } & 0.3983 & 0.2501 & 0.4314 & 0.2451 & 0.3127 & 0.2838 \\
\hline & $(0.0968)^{*}$ & $(0.0851)^{*}$ & $(0.1182)^{*}$ & $(0.0759)^{*}$ & $(0.1221)^{*}$ & $(0.0749)^{*}$ \\
\hline \multirow[t]{2}{*}{ A-Levels } & 0.1832 & 0.2122 & 0.1495 & 0.2188 & 0.0846 & 0.2224 \\
\hline & $(0.0651)^{*}$ & $(0.0360)^{*}$ & $(0.0800)+$ & $(0.0341)^{*}$ & $(0.0865)$ & $(0.0337)^{*}$ \\
\hline \multirow[t]{2}{*}{ O-Levels/GCSE’s } & 0.1202 & 0.3185 & -0.0207 & 0.3400 & -0.0958 & 0.3518 \\
\hline & $(0.1308)$ & $(0.0946)^{*}$ & $(0.1552)$ & $(0.0885)^{*}$ & $(0.1536)$ & $(0.0890)^{*}$ \\
\hline \multirow[t]{2}{*}{ CSE's } & 0.1776 & 0.1178 & 0.1602 & 0.1261 & 0.1408 & 0.1271 \\
\hline & $(0.0710)^{*}$ & $(0.0386)^{*}$ & $(0.0802)^{*}$ & $(0.0374)^{*}$ & $(0.0800)+$ & $(0.0376)^{*}$ \\
\hline \multirow[t]{2}{*}{ Experience } & 0.0159 & 0.0160 & 0.0088 & 0.0171 & 0.0134 & 0.0163 \\
\hline & $(0.0049)^{*}$ & $(0.0027)^{*}$ & $(0.0062)$ & $(0.0025)^{*}$ & $(0.0058) *$ & $(0.0025)^{*}$ \\
\hline \multirow[t]{2}{*}{ Experience squared } & -0.0002 & -0.0002 & -0.00004 & -0.0002 & -0.0001 & -0.0002 \\
\hline & $(0.0001)^{*}$ & $(0.00004)^{*}$ & $(0.0001)$ & $(0.00004)^{*}$ & $(0.0001)$ & $(0.00004) *$ \\
\hline \multirow[t]{2}{*}{ Professional/managerial } & 0.3833 & 0.4051 & 0.3770 & 0.4094 & 0.4300 & 0.3976 \\
\hline & $(0.0779)^{*}$ & $(0.0519)^{*}$ & $(0.0877)^{*}$ & $(0.0498)^{*}$ & $(0.0901)^{*}$ & $(0.0496)^{*}$ \\
\hline \multirow[t]{2}{*}{ Skilled } & 0.1483 & 0.1044 & 0.1184 & 0.1191 & 0.1956 & 0.1045 \\
\hline & $(0.0793)+$ & $(0.0485)^{*}$ & $(0.0952)$ & $(0.0463)^{*}$ & $(0.1013)+$ & $(0.0459)^{*}$ \\
\hline \multirow[t]{2}{*}{ Semi-skilled } & 0.1409 & 0.1143 & 0.1722 & 0.1143 & 0.1932 & 0.1100 \\
\hline & $(0.0680)^{*}$ & $(0.0424)^{*}$ & $(0.0823)^{*}$ & $(0.0403)^{*}$ & $(0.0841)^{*}$ & $(0.0400)^{*}$ \\
\hline \multirow[t]{2}{*}{ Public sector } & 0.0942 & 0.0668 & 0.0732 & 0.0738 & 0.0798 & 0.0720 \\
\hline & $(0.0553)+$ & $(0.0355)+$ & $(0.0669)$ & $(0.0334)^{*}$ & $(0.0690)$ & $(0.0333) *$ \\
\hline \multirow{2}{*}{$\begin{array}{l}\text { Transport and } \\
\text { communications }\end{array}$} & -0.0979 & -0.2198 & -0.1631 & -0.2026 & -0.2164 & -0.1976 \\
\hline & $(0.0680)$ & $(0.0364)^{*}$ & $(0.0849)+$ & $(0.0346)^{*}$ & $(0.0847)^{*}$ & $(0.0346)^{*}$ \\
\hline \multirow{2}{*}{$\begin{array}{l}\text { Employer 100-999 } \\
\text { Emnlovees }\end{array}$} & 0.0348 & 0.0800 & -0.0082 & 0.0797 & -0.0076 & 0.0784 \\
\hline & $(0.0575)$ & $(0.0309)^{*}$ & $(0.0714)$ & $(0.0294)^{*}$ & $(0.0753)$ & $(0.0295)^{*}$ \\
\hline Employer $\geq 1000$ & 0.1220 & 0.1118 & 0.0579 & 0.1255 & 0.0625 & 0.1157 \\
\hline \multirow{3}{*}{$\begin{array}{c}\text { Employees } \\
\text { Trade union member }\end{array}$} & $(0.0667)+$ & $(0.0437)^{*}$ & $(0.0792)$ & $(0.0414)^{*}$ & $(0.0835)$ & $(0.0410)^{*}$ \\
\hline & 0.1907 & 0.1411 & 0.1577 & 0.1459 & 0.1599 & 0.1476 \\
\hline & $(0.0502)^{*}$ & $(0.0299)^{*}$ & $(0.0596)^{*}$ & $(0.0284)^{*}$ & $(0.0621)^{*}$ & $(0.0283)^{*}$ \\
\hline \multirow[t]{2}{*}{ Female } & -0.1753 & -0.1730 & -0.1408 & -0.1821 & -0.0824 & -0.1889 \\
\hline & $(0.0504)^{*}$ & $(0.0283)^{*}$ & $(0.0612)^{*}$ & $(0.0270)^{*}$ & $(0.0644)$ & $(0.0269)^{*}$ \\
\hline \multirow[t]{2}{*}{ Ethnic minority } & 0.0563 & -0.1317 & -0.0129 & -0.1142 & 0.0038 & -0.1138 \\
\hline & (0.0919) & $(0.0424)^{*}$ & $(0.1166)$ & $(0.0405)^{*}$ & $(0.1221)$ & $(0.0405)^{*}$ \\
\hline \multirow[t]{2}{*}{ Married/cohabiting } & 0.1456 & 0.0908 & 0.1722 & 0.0859 & 0.1635 & 0.0831 \\
\hline & $(0.0564)^{*}$ & $(0.0307)^{*}$ & $(0.0686)^{*}$ & $(0.0293)^{*}$ & $(0.0714)^{*}$ & $(0.0290)^{*}$ \\
\hline \multirow[t]{2}{*}{ Intercept } & 1.0843 & 1.2880 & 1.1666 & 1.2778 & 1.0944 & 1.2955 \\
\hline & $(0.1021)^{*}$ & $(0.0607)^{*}$ & $(0.1163)^{*}$ & $(0.0574)^{*}$ & $(0.1193)^{*}$ & $(0.0576)^{*}$ \\
\hline Lambda & 0.1132 & 0.0306 & 0.1038 & -0.0033 & 0.1184 & -0.0235 \\
\hline & $(0.0428)^{*}$ & $(0.0557)$ & $(0.0463)^{*}$ & $(0.0599)$ & $(0.0481)^{*}$ & $(0.0620)$ \\
\hline Wald $\operatorname{chi}^{2}(36)$ & $314.49 *$ & $661.16^{*}$ & $232.28 *$ & $760.96^{*}$ & $233.07 *$ & 757.98* \\
\hline
\end{tabular}


Table 4 (continued)

\begin{tabular}{|c|c|c|c|c|}
\hline \multirow{3}{*}{ Sample } & (7) & $(8)$ & (9) & (10) \\
\hline & \multicolumn{2}{|c|}{... and writes Welsh } & \multicolumn{2}{|c|}{ Uses Welsh at work } \\
\hline & Yes & No & Yes & No \\
\hline $\mathrm{N}$ & 150 & 864 & 149 & 865 \\
\hline \multirow[t]{2}{*}{ Degree } & 0.3733 & 0.4178 & 0.4684 & 0.3930 \\
\hline & $(0.0900) *$ & $(0.0464) *$ & $(0.0914) *$ & $(0.0460) *$ \\
\hline \multirow[t]{2}{*}{ HND } & 0.3224 & 0.2800 & 0.5398 & 0.2194 \\
\hline & $(0.1286) *$ & $(0.0732)^{*}$ & $(0.1246) *$ & $(0.0744) *$ \\
\hline \multirow[t]{2}{*}{ A-Levels } & 0.1022 & 0.2225 & 0.0036 & 0.2258 \\
\hline & $(0.0943)$ & $(0.0332)^{*}$ & $(0.0912)$ & $(0.0333) *$ \\
\hline \multirow[t]{2}{*}{ O-Levels/GCSE's } & -0.1810 & 0.3550 & 0.0389 & 0.3183 \\
\hline & $(0.1690)$ & $(0.0860)^{*}$ & $(0.1602)$ & $(0.0880)^{*}$ \\
\hline \multirow[t]{2}{*}{ CSE's } & 0.1365 & 0.1262 & 0.1859 & 0.1249 \\
\hline & $(0.0831)+$ & $(0.0374)^{*}$ & $(0.0923)^{*}$ & $(0.0363)^{*}$ \\
\hline \multirow[t]{2}{*}{ Experience } & 0.0038 & 0.0172 & 0.0175 & 0.0162 \\
\hline & $(0.0069)$ & $(0.0025)^{*}$ & $(0.0065)^{*}$ & $(0.0025)^{*}$ \\
\hline \multirow[t]{2}{*}{ Experience squared } & 0.00003 & -0.0002 & -0.0003 & -0.0002 \\
\hline & $(0.0001)$ & $(0.00004)^{*}$ & $(0.0001)^{*}$ & $(0.00004)^{*}$ \\
\hline \multirow[t]{2}{*}{ Professional/managerial } & 0.4894 & 0.3866 & 0.3093 & 0.4170 \\
\hline & $(0.0946)^{*}$ & $(0.0484)^{*}$ & $(0.0969)^{*}$ & $(0.0485)^{*}$ \\
\hline \multirow[t]{2}{*}{ Skilled } & 0.2416 & 0.1026 & 0.1053 & 0.1172 \\
\hline & $(0.1044)^{*}$ & $(0.0457)^{*}$ & $(0.1029)$ & $(0.0454)^{*}$ \\
\hline \multirow[t]{2}{*}{ Semi-skilled } & 0.1842 & 0.1113 & 0.0891 & 0.1229 \\
\hline & $(0.0854)^{*}$ & $(0.0398)^{*}$ & $(0.0882)$ & $(0.0396)^{*}$ \\
\hline \multirow[t]{2}{*}{ Public sector } & 0.0945 & 0.0732 & 0.1177 & 0.0656 \\
\hline & $(0.0720)$ & $(0.0329)^{*}$ & $(0.0742)$ & $(0.0332)^{*}$ \\
\hline \multirow{2}{*}{$\begin{array}{l}\text { Transport and } \\
\text { communications }\end{array}$} & -0.2072 & -0.1978 & -0.1065 & -0.2105 \\
\hline & $(0.0862)^{*}$ & $(0.0342)^{*}$ & $(0.0920)$ & $(0.0341)^{*}$ \\
\hline \multirow{2}{*}{$\begin{array}{r}\text { Employer 100-999 } \\
\text { employees }\end{array}$} & -0.0842 & 0.0835 & 0.0206 & 0.0766 \\
\hline & $(0.0790)$ & $(0.0288)^{*}$ & $(0.0819)$ & $(0.0285)^{*}$ \\
\hline \multirow{2}{*}{$\begin{array}{l}\text { Employer } \geq 1000 \\
\text { employees }\end{array}$} & 0.0795 & 0.1128 & 0.1444 & 0.1124 \\
\hline & $(0.0878)$ & $(0.0403)^{*}$ & $(0.0999)$ & $(0.0397)^{*}$ \\
\hline \multirow[t]{2}{*}{ Trade union member } & 0.1745 & 0.1456 & 0.1874 & 0.1485 \\
\hline & $(0.0654)^{*}$ & $(0.0280)^{*}$ & $(0.0687)^{*}$ & $(0.0277)^{*}$ \\
\hline \multirow[t]{2}{*}{ Female } & -0.0773 & -0.1873 & -0.2486 & -0.1677 \\
\hline & $(0.0659)$ & $(0.0265)^{*}$ & $(0.0684)^{*}$ & $(0.0264)^{*}$ \\
\hline \multirow[t]{2}{*}{ Ethnic minority } & 0.0156 & -0.1161 & 0.3044 & -0.1286 \\
\hline & $(0.1315)$ & $(0.0399) *$ & $(0.1423)^{*}$ & $(0.0396)^{*}$ \\
\hline \multirow[t]{2}{*}{ Married/cohabiting } & 0.1727 & 0.0877 & 0.1687 & 0.0847 \\
\hline & $(0.0746) *$ & $(0.0287)^{*}$ & $(0.0793) *$ & $(0.0284) *$ \\
\hline \multirow[t]{2}{*}{ Intercept } & 1.1688 & 1.2833 & 1.2135 & 1.2800 \\
\hline & $(0.1230) *$ & $(0.0565)^{*}$ & $(0.1200)^{*}$ & $(0.0553) *$ \\
\hline \multirow[t]{2}{*}{ Lambda } & 0.1226 & -0.0264 & 0.0622 & 0.0266 \\
\hline & $(0.0502)^{*}$ & $(0.0615)$ & $(0.0508)$ & $(0.0564)$ \\
\hline Wald $\operatorname{chi}^{2}(36)$ & $232.07 *$ & $772.65^{*}$ & $228.42 *$ & $796.23 *$ \\
\hline
\end{tabular}

Source: computed from British Household Panel Survey 1999

+ denotes significant at $10 \%$; $*$ at $5 \%$.

Wald $\mathrm{chi}^{2}(36)$ is a test for the joint significance of the explanatory variables. 
Table 5: Earnings Differential Decompositions

\begin{tabular}{|c|c|c|c|c|c|}
\hline Sample partition: & $\begin{array}{l}\text { Understands } \\
\text { spoken } \\
\text { Welsh }\end{array}$ & $\begin{array}{l}\text {...and } \\
\text { speaks } \\
\text { Welsh }\end{array}$ & $\begin{array}{l}\ldots \text { and } \\
\text { reads } \\
\text { Welsh }\end{array}$ & $\begin{array}{l}\ldots \text { and } \\
\text { writes } \\
\text { Welsh }\end{array}$ & $\begin{array}{c}\text { Uses } \\
\text { Welsh at } \\
\text { work }\end{array}$ \\
\hline $\begin{array}{l}\text { ln (hourly earnings) } \\
\text { differential }\end{array}$ & 0.0791 & 0.0911 & 0.0970 & 0.0956 & 0.0326 \\
\hline $\begin{array}{c}\text { Selectivity effect } \\
(\%)\end{array}$ & $\begin{array}{r}0.1008 \\
(127.4)\end{array}$ & $\begin{array}{r}0.1100 \\
(120.7)\end{array}$ & $\begin{array}{r}0.1348 \\
(139.0)\end{array}$ & $\begin{array}{r}0.1426 \\
(149.1)\end{array}$ & $\begin{array}{r}0.0589 \\
(181.0)\end{array}$ \\
\hline $\begin{array}{c}\text { Bilingual (dis)advantage } \\
(\%)\end{array}$ & $\begin{array}{r}-0.0438 \\
(-55.4)\end{array}$ & $\begin{array}{r}-0.0495 \\
(-54.3)\end{array}$ & $\begin{array}{r}-0.0614 \\
(-63.3)\end{array}$ & $\begin{array}{r}-0.0620 \\
(-64.8)\end{array}$ & $\begin{array}{l}-0.0544 \\
(-167.0)\end{array}$ \\
\hline $\begin{array}{l}\text { Anglophone (dis)advantage } \\
(\%)\end{array}$ & $\begin{array}{r}-0.0137 \\
(-17.4)\end{array}$ & $\begin{array}{r}-0.0108 \\
(-11.9)\end{array}$ & $\begin{array}{r}-0.0120 \\
(-12.4)\end{array}$ & $\begin{array}{r}-0.0108 \\
(-11.3)\end{array}$ & $\begin{array}{r}-0.0094 \\
(-28.8)\end{array}$ \\
\hline $\begin{array}{c}\text { Endowments } \\
\qquad(\%)\end{array}$ & $\begin{array}{r}0.0359 \\
(45.3)\end{array}$ & $\begin{array}{r}0.0415 \\
(45.5)\end{array}$ & $\begin{array}{r}0.0357 \\
(36.8)\end{array}$ & $\begin{array}{r}0.0258 \\
(27.0)\end{array}$ & $\begin{array}{r}0.0374 \\
(114.8)\end{array}$ \\
\hline \multicolumn{6}{|l|}{ of which: } \\
\hline Education & 0.0219 & 0.0259 & 0.0260 & 0.0239 & 0.0260 \\
\hline Experience & -0.0036 & -0.0105 & -0.0164 & -0.0168 & -0.0097 \\
\hline Occupation & 0.0063 & 0.0157 & 0.0197 & 0.0121 & 0.0139 \\
\hline Public Sector & 0.0065 & 0.0073 & 0.0071 & 0.0073 & 0.0098 \\
\hline Transport & 0.0061 & 0.0074 & 0.0056 & 0.0035 & 0.0064 \\
\hline Workplace size & -0.0056 & -0.0056 & -0.0074 & -0.0081 & -0.0107 \\
\hline Trade union member & 0.0010 & -0.0003 & -0.0011 & -0.0009 & -0.0029 \\
\hline Gender & -0.0083 & -0.0115 & -0.0126 & -0.0113 & -0.0108 \\
\hline Ethnicity & 0.0102 & 0.0123 & 0.0134 & 0.0145 & 0.0124 \\
\hline Marital status & 0.0013 & 0.0007 & 0.0014 & 0.0015 & 0.0028 \\
\hline
\end{tabular}

Source: Computed from British Household Panel Survey, 1999, using estimates reported in Table 4. 